
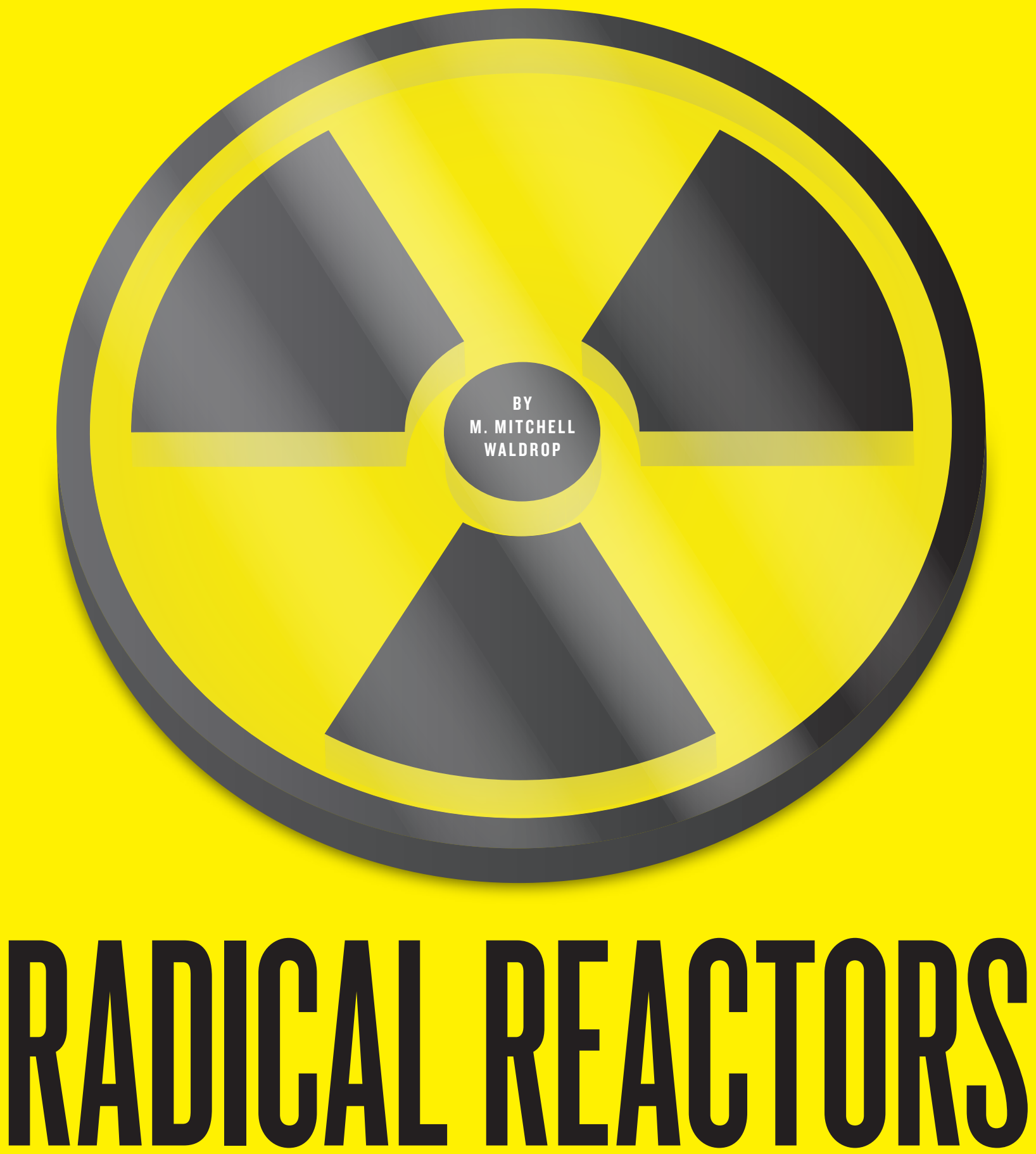

For decades, one design has dominated nuclear reactors while potentially better options were left by the wayside. Now, the alternatives might finally have their day.

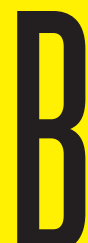

ack in 2000, when Kirk Sorensen was a NASA engineer looking at nuclearpower options for future colonies on the Moon, he came across a book that described the molten-salt reactor: an energy source in which the nuclear fuel was liquid.

It sounded bizarre, says Sorensen. Every reactor he had ever heard of used some form of solid uranium fuel - starting with the 'light-water' 
reactors that currently dominate the nuclearpower industry. But the book explained that the molten-salt technology had been demonstrated some three decades earlier at the Oak Ridge National Laboratory in Tennessee - and that the fluid uranium- or thorium-containing fuel offered major advantages. Molten-salt reactors would be impervious to catastrophic meltdown, for example, and instead of producing nuclear waste laced with plutonium and other longlived radioisotopes, they could destroy those isotopes almost completely.

The list of advantages went on and on, says Sorensen: the molten-salt idea "had the potential to solve almost all the problems of nuclear energy in a far, far more elegant way" than light-water reactors. "So why didn't we do it this way in the first place?"

A lot of people have been asking that question in the past decade - and not just about the molten-salt reactor. That particular technology was abandoned in 1976 because of warring agendas within the US research programme. But it was just one of several alternative technologies to be sidelined during the first rush to commercialize nuclear power. Others include 'fast' reactors that would also burn up nuclear waste, and high-temperature reactors that could take a huge bite out of greenhouse-gas emissions by generating zero-carbon heat for industry. Taken together, these alternative technologies could eliminate most or all of nuclear energy's drawbacks. But they have received only fitful attention from researchers over the decades, thanks to constantly shifting agendas and funding levels.

Now, change may be coming. Over the past decade, the need for safe, carbon-free energy - especially in fast-developing nations such as China - has sparked government interest in alternative nuclear technologies, along with commercial efforts to revive and market some designs. Optimists think that even the nuclear disaster at the Fukushima Daiichi power plant in Japan last year will ultimately boost the market for safer alternative reactors. From start-ups such as Flibe Energy, which Sorensen founded last year in Huntsville, Alabama, to commercialize the molten-salt reactor, to industry giants such as General Electric-Hitachi Nuclear Energy, which is developing a commercial fast reactor, companies hope to be ready.

Reviving the technologies will not be quick or easy. Although the basic designs were worked out decades ago, engineers hoping to put them into practice must develop things such as radiation-resistant materials, moreefficient heat exchangers and improved safety systems - and must then prove to regulators that all these systems will work. "Nuclear

$\rightarrow$ NATURE.COM Hear more about radical reactors on Nature's podcast: go.nature.com/jqcno5 expensive. It's slow. And the stakes are very high, because safety has to be a factor."

But those involved share a conviction that the best hope for the nuclear industry's future is to reclaim its past. As Sorensen points out about the cancellation of the molten-salt programme: "Nobody ever said, 'Maybe we made a mistake. Maybe we should go back and revisit that decision."

\section{FIRST, NOT BEST}

Light-water reactors achieved their dominance not because they were best, but because they were first. Originally developed in the late 1940 s as a compact power source for nuclear ships and submarines, the light-water design was adapted and scaled up during the 1950s, when the United States sought to put a peaceful face on atomic energy by creating a commercial nuclear-power industry. 'Light water' is ordinary $\mathrm{H}_{2} \mathrm{O}$, which flows through the reactor core, absorbs its heat and circulates it to a conventional steam turbine that turns the heat into electricity (see 'The nuts and bolts of nuclear').

Eventually, such reactors were meant to be part of a larger system that would make up for a basic inefficiency: left alone, any nuclear reactor will quickly poison itself. As the chain reaction proceeds, the fuel accumulates more and more of the fragments left over after the uranium atoms split, which in turn absorb more and more of the neutrons required to keep the reaction going. After perhaps 18 months, the fuel is 'spent' and has to be removed - even though it still contains much of its original energy.

"So there was always this vision that there would be a recycled-spent-fuel infrastructure that would allow you to recover more of the fuel's energy," says William Magwood, a former director of the Office of Nuclear Energy at the US Department of Energy (DOE) and now a member of the US Nuclear Regulatory Commission. A worldwide network of reprocessing plants would take the spent fuel, chemically extract the still-usable components - mostly uranium-235, plus the fissionable plutonium-239 formed when neutrons are captured by non-fissile uranium-238 - and then turn them into fresh reactor fuel. Ultimately, the plan was to transition to a new generation of 'breeder' reactors designed to maximize plutonium production. The only waste would be a comparatively small residue of intensely radioactive fission products that would decay within a few centuries, and could be disposed of in, say, a well-designed concrete bunker.

This vision became the dominant US strategy in the 1960s and early 1970s, says Magwood, to the point at which authorities terminated much of the research funding for non-breeder reactor designs - including the molten-salt reactor. And the scheme took off: of the 437 nuclearpower reactors currently operating around the world, 356 are light-water reactors.

But then, in May 1974, India tested a nuclear bomb made with plutonium extracted from reactor fuel. Governments around the world suddenly had to face the geopolitical realities: large-scale commercial reprocessing would invite rampant nuclear-weapons proliferation. Because each reprocessing plant would be working with bomb-grade plutonium by the tonne, how could inspectors ever be sure that no one had diverted the 4-6 kilograms required for a weapon?

So in April 1977, US President Jimmy Carter banned commercial reprocessing. President Ronald Reagan lifted that ban a few years later, but the costs of the facilities were so high that only two commercial reprocessing plants have been opened for reactor fuel since then, both in France. Research on breeder reactors largely ceased, because they seemed to make little sense without reprocessing. And engineers found themselves left with a complicated disposal problem: they would now have to isolate tens of thousands of tonnes of spent fuel for hundreds of centuries, thanks to the 24,100 year half-life of plutonium-239. No one has yet worked out how to guarantee isolation on that timescale (see Nature 473, 266-267; 2011).

Meanwhile, the 1970 s also brought an increasing outcry over safety. If the flow of water through a light-water reactor is interrupted for any reason, then heat becomes trapped in the core. Even if the reactor is technically shut down, the fission products can still produce enough heat from radioactive decay to melt the fuel and escape into the environment. All lightwater reactors have emergency back-up cooling systems - but what if those systems fail? That fear was realized in March 1979, when an accidental loss of coolant triggered a partial meltdown at the Three Mile Island nuclear power plant near Harrisburg, Pennsylvania - and dramatically confirmed at Fukushima Daiichi, which saw a complete meltdown in March 2011 (see Nature 483, 138-140; 2012).

\section{A SECOND CHANCE}

The public and political backlash after the Three Mile Island incident created a worldwide 'nuclear brown-out' that lasted for a quarter of a century. Power companies scrapped their nuclear expansion plans and cancelled almost all of their reactor orders. And the industry became even more reluctant to explore new technologies. "The industry is risk-averse to moving beyond technology and materials they have lots of experience with" and that they know can get regulatory approval, says Per Peterson, a nuclear engineer at the University of California, Berkeley.

With little interest from industry and no practical hope for deployment, advancedreactor research struggled with inconsistent direction and support. "It's very hard to do planning and advanced engineering R\&D if you're up and down, up and down," says Michael Corradini, a nuclear engineer at the University of Wisconsin-Madison.

This picture didn't begin to change 
- until around the turn of the millennium. "Nuclear construction had taken off in China and south Asia - any place that doesn't have oil and gas," recalls Charles Forsberg, a nuclear engineer at the Massachusetts Institute of Technology (MIT) in Cambridge. (There are currently 64 reactors under construction around the world, with hundreds more planned.) In the United States, he says, "the feds realized that, if we're not doing anything on nuclear, we won't be at the table". Climate change, too, drove renewed interest in nuclear technology in the United States and Europe. Given the erratic output of both wind and solar generators, says Forsberg, "if you're going to get off fossil fuel, you have to have a serious nuclear programme".

\section{RADICAL INVESTMENT}

One result of this renewed focus was the US Nuclear Power 2010 programme. Announced by the DOE in February 2002, this government-industry cost-sharing plan was designed to help manufacturers to develop and license light-water reactors with advanced safety features, such as the ability to keep the coolant moving during an accident, using gravity and natural convection. Several such reactors are now being planned around the world, including four under construction in the United States - the first new reactors there in a generation.

Even more radical designs might find an opening with the DOE's cost-sharing programme for Small Modular Reactor development, launched this year. That scheme's goal is to move away from the current multi-gigawatt nuclear plants, which can cost between US $\$ 10$ billion and $\$ 15$ billion to build, towards plants of 250 megawatts or less - small enough to mass-produce in a factory and ship to the intended site. Four reactor vendors, all with advanced light-water designs, competed for what the name implies: they generate steam at up to $1,000^{\circ} \mathrm{C}$, much hotter than the roughly $300^{\circ} \mathrm{C}$ available from light-water reactors. This requires some radically different design choices, such as the use of helium gas instead of water to extract heat, and the use of a heat-resistant fuel made from oxides and carbides of uranium.

Such reactors cannot melt down: the fuel is stable up to $1,600^{\circ} \mathrm{C}$, hundreds of degrees hotter than the core would become even if all power and coolant were lost. The high temperatures would make the reactors more efficient at producing electricity. And they could slash carbon emissions by supplying heat for industrial processes. In the United States, roughly $23 \%$ of all energy is used in industrial applications such as petroleum cracking and plastics manufacture, many of which need temperatures of at least $700^{\circ} \mathrm{C}$. Currently, those temperatures tend to be generated by burning natural gas; high-temperature reactors could provide a zero-carbon alternative.

A number of commercial high-temperature reactors are under development around the world. But this year, a consortium of petrochemical companies and reactor manufacturers agreed to back the Antares hightemperature reactor design from the French company AREVA, based in Paris. "All that's left is about $\$ 800$ million of work design and licensing effort required to get the technology to the point where the Nuclear Regulatory Commission could approve it," says Fred Moore, head of the division that provides power and steam for the Dow Chemical Company, headquartered in Midland, Michigan. He estimates that this should take 5-7 years. If all goes to plan, high-temperature systems will be among the first advanced reactors to be deployed, starting in the 2020s.

Not far behind would be fast reactors, which tackle a problem that high-temperature reactors cannot: spent nuclear fuel. Fast reactors

that collectively make disposal of spent fuel a nightmare. Fast neutrons, by contrast, rarely get absorbed. They don't hit their targets often, but when they do, that target almost always splits. As a result, fast reactors not only avoid the problem of producing long-lived isotopes, but can even destroy them in spent fuel.

Building a fast reactor is tricky, says Peterson, not least because it has to be cooled by liquid sodium or some other substance that won't slow the neutrons down as water does. This can make for a bulky design. "And it's very challenging to build heat exchangers" to make steam for the power turbines, he says, because sodium reacts violently with moisture to produce explosive hydrogen gas. Researchers are actively studying other, less reactive options for cooling, such as lead and supercritical carbon dioxide, he says.

Nevertheless, some 20 fast reactors have been operated over the years - many of them following the 1970s breeder design that was built to maximize plutonium production instead of consuming it - and at least four manufacturers are developing small fast reactors for spentfuel consumption. A leading example is the Super Power Reactor Innovative Small Module (S-PRISM) from General Electric-Hitachi in Wilmington, North Carolina. It calls for a compact sodium-cooled fast reactor, integrated with a recycling unit that would take the reactor's spent fuel, remove the fission products that poison the nuclear reaction, and put the rejuvenated fuel back into the reactor. At no point would it isolate bomb-ready plutonium.

The potential market is substantial, says Eric Loewen, head of advanced-reactor development for General Electric-Hitachi. "We have a usability study going on with the United Kingdom, where we would take the 100 tonnes of plutonium from their reprocessing plants and turn it into an energy resource," he says. And in the United States and elsewhere, he says, "our vision is a network of advanced recycling centres", each with six S-PRISM reactors and one recycling centre that could keep up with the waste from between one and three light-water reactors, and get rid of the backlog currently sitting in storage.

That network will not be cheap. But the fundamental challenge is

the award, which on 20 November went to a consortium headed by the Babcock and Wilcox Company of Charlotte, North Carolina.

But other designs could also benefit, says Peterson. "If we can generate a market for light-water small modular reactors," he says, "that makes it much easier to develop a market for prototype advanced reactors." Power companies could experiment with the new technology by simply sliding in another module. If it works, great, says Peterson. If it doesn't, not much has been lost. "This lowers their whole risk threshold," he says.

Prime candidates for slide-in modules are high-temperature reactors, which do exactly could consume the stuff, turning waste into energy and easing the disposal problem.

Fission neutrons are 'fast' when they have just emerged from newly split nuclei at a mean energy of roughly 2 million electronvolts. In light-water reactors, collisions with the hydrogen nuclei in the coolant water quickly slow the neutrons to just a fraction of an electron volt, which makes them more likely to trigger another fission reaction. But slow neutrons have a drawback: instead of splitting the target uranium nuclei, they often get absorbed, transforming the nuclei into long-lived isotopes of plutonium, neptunium, americium, curium or other heavy elements - the ones political, says Loewen, echoing Forsberg and many other experts: what is needed is "a policy framework that lets people see spent fuel as an asset, rather than something to be thrown away."

\section{MOLTEN-SALT REACTORS}

The great virtue of solid reactor fuel is its predictable geometry. The great drawback is its complexity. The intensity of neutron bombardment, the distribution of fission products, the radiation damage to the fuel's crystalline structure: everything varies from point to point. This is a constant headache for designers trying to ensure that the reactor operation 


\section{THE NUTS AND BOLTS OF NUCLEAR}

All nuclear reactors rely on fission to make heat, which can be used for generating electricity. But engineers have come up with many alternatives to the commonly used light-water reactor.

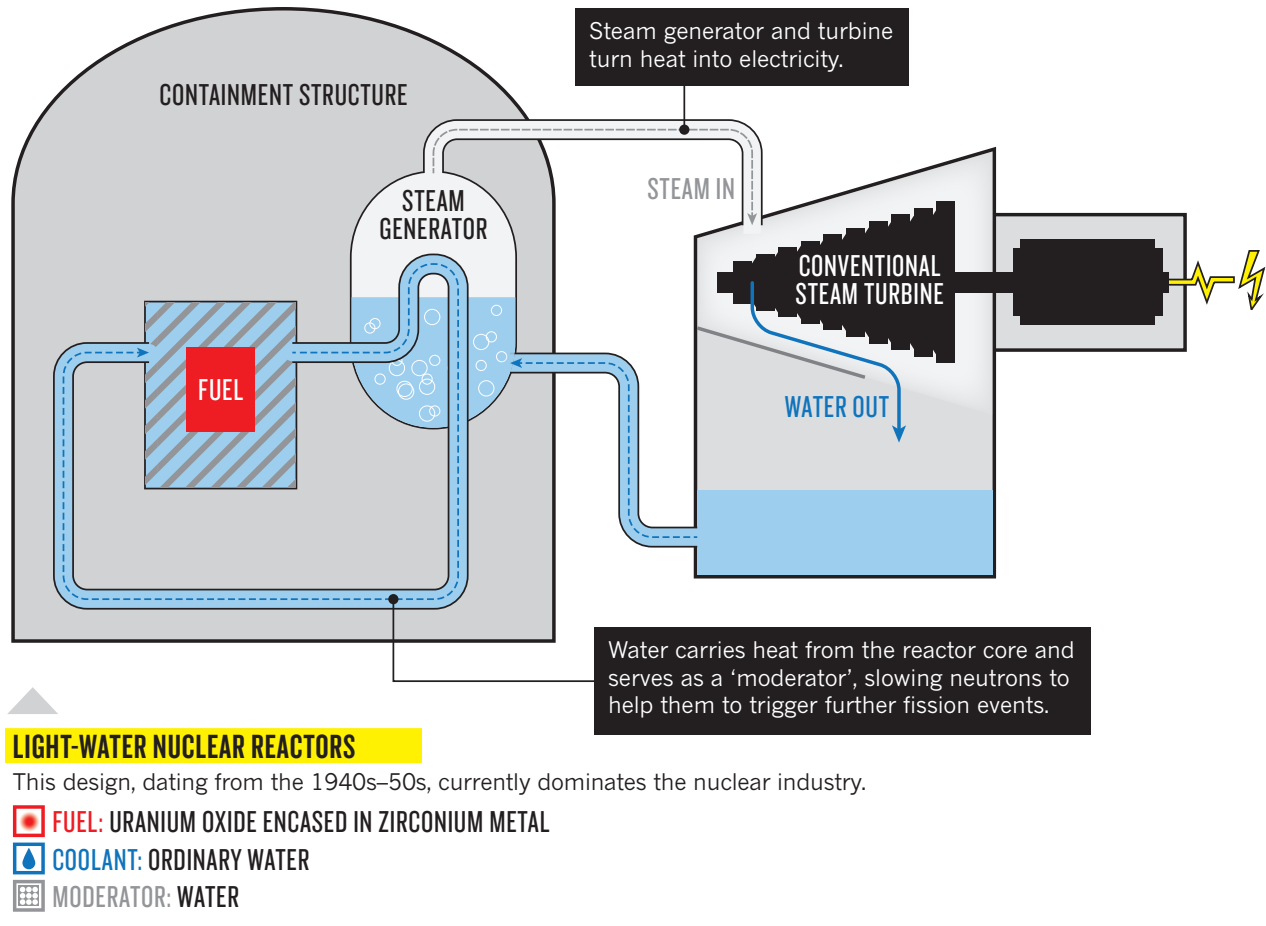

\section{ADVANCED REACTORS}

These decades-old reactor designs have been revived and modernized in recent years.

\section{HIGH-TEMPERATURE REACTORS \\ Deliver heat at up to $950{ }^{\circ} \mathrm{C}$ for industry, cutting carbon emissions. \\ - URANIUM OXIDE/CARBIDE MIX COATED WITH SILICON CARBIDE: STABLE TO $1,600^{\circ} \mathrm{C}$ \\ (1) HELIUM GAS OR FLIBE (MIXTURE OF LITHIUM FLUORIDE AND BERYLLIUM FLUORIDE) \\ GRAPHITE \\ FAST REACTORS \\ Use unmoderated 'fast' neutrons to burn up heavy elements in spent nuclear fuel.

$\square$ METALLIC OR CERAMIC-CLAD URANIUM
HELIUM GAS; LIQUID SODIUM METAL;
MOLTEN LEAD; OR MOLTEN
LEAD-BISMUTH MIX
NONE

\section{MOLTEN-SALT REACTORS}

se liquid fuel to increase safety and minimize long-term nuclear wastes.

- URANIUM OR THORIUM FLUORIDE

C) FLIBE

GRAPHITE is stable - and trying to convince regulators that even the worst meltdown won't allow any part of the fuel to collapse into a critical mass.

But all these concerns go away when the fuel is already a liquid - one major reason why Oak Ridge wanted to develop the molten-salt reactor back in the 1960s. 'Molten-salt' refers to the fuel, usually uranium tetrafluoride, which is liquid at operating temperatures when blended with 'FLiBe': a mixture of lithium fluoride and beryllium fluoride that serves as a coolant. "It's a pot - a big, dumb, pot," says Forsberg. "You throw fuel in, it's mixed, and the overall composition changes not at all."

Liquid fuel has another big advantage, says Sorensen: "You don't have to remove it from the reactor until it's completely consumed." Instead, the fuel is circulated through an external recycling unit that extracts the fission products continuously, keeping the fuel from being poisoned. The design also allows for an elegant approach to safety, says Sorensen: at the bottom of the reactor is a hole, plugged with a chunk of fuel that is kept solid by a refrigeration unit. If the reactor loses power in an emergency, the refrigeration will cease, the plug will melt and the fuel will safely drain into underground holding tanks. Finally, the molten-salt design can accommodate a variety of fuels, ranging from conventional uranium to raw nuclear waste or thorium - an element that is roughly three times more abundant than uranium.

For all of that, reviving the molten-salt reactor after a four-decade hiatus is a daunting task. "We have to rebuild a knowledge base that has largely gone away," says Sorensen. He founded Flibe Energy to try, though. The company is developing a 40-megawatt reactor that might be used on military bases so that they can operate independently of the grid.

\section{SOLID CHANCE}

In September 2011, Forsberg, Peterson, MIT's Lin-wen Hu and Todd Allen, a nuclear engineer at the University of Wisconsin-Madison, became principal investigators on a 3-year, DOE-funded project that could be a step on the way to the molten-salt reactor: a FLiBe-cooled high-temperature reactor. "No one has ever built a salt-cooled solid-fuel reactor," says Peterson. But if the project works, the reactor core could be four to five times smaller than those in other designs and, because of the stability of the FLiBe salt, it would "always be hundreds of degrees below the failure limits", he says.

Peterson says that the company could have a test reactor within a decade, although "that assumes abundant resources". That is a big assumption: the global economic crisis has made financing for all advanced reactors much harder to come by. Furthermore, notes Corradini, pointing to the sudden abundance of shale gas in the United States, "cheap fossil fuels have postponed many of the clean-energy projects in the United States, not just nuclear". Paul Genoa, director of policy development for the Nuclear Energy Institute trade group in Washington DC, takes the long view. "We did the light-water reactors first, to get going," he says. Next, in the 2020s, will come advanced light-water reactors for increased safety, followed closely by high-temperature reactors that expand the attack on carbon emissions. "And then we build fast reactors to consume the waste."

Molten-salt reactors are something of a wild card, says Genoa, but are worth developing. Some even wilder cards are under investigation: one notable example is the acceleratordriven reactor, which would drive fission reactions using neutrons from a high-energy particle accelerator. It could be fuelled with thorium, and shut down instantly by switching off the accelerator.

But will nuclear energy really evolve? Those in the field see reason for optimism, particularly if the increasingly tangible consequences of climate change force governments to put a price on carbon. Even the Fukushima disaster could ultimately spur new nuclear technologies, says Genoa. "It scared people and made them concerned about nuclear energy," he says. But as people looked more closely, "they said, 'Hey, those were 30 -year-old plants"'. In time, he says, smart, new reactors will look a whole lot more appealing. a SEE COMMENT P.31

M. Mitchell Waldrop is a features editor for Nature in Washington DC. 